\title{
Academy elections in a muddle
}

The Soviet Academy of Sciences has been made a laughing-stock by the muddle over its constituency election for the Supreme Soviet. But the difficulty should have been anticipated.

THE continuing pantomime (see page 364 ) of the failure of the Soviet Academy of Sciences to elect a score of people as its representatives in the new Chamber of the People's Deputies is neither a surprise nor a criticism of the academy. On the contrary, it may more properly be regarded as a sign of grace. The academy's failure even to nominate enough people to fill the 25 places it had been offered in the new chamber (in the end, there were only 23 nominees, so that five places were relinquished) is a measure of the diversity of opinion within the academy, and of its members' willingness to behave as they believe. Is that not a virtue, rather than the opposite?

Even so, the conduct of the election, and its outcome, will not enhance the academy's reputation within the Soviet Union or elsewhere. Nor will it do much for the reputation of the Soviet electoral system, hastily devised last year as part of the cutting edge of perestroika. There are too many wheels within wheels for anybody's comfort. One difficulty is that there are too many kinds of constituencies. Some are geographical, some geographical constituencies include groups of others, while other constituencies are professional (such as the academy) or defined by other special interests (such as the company of Soviet philatelists). Another difficulty is that the rules by which professional and other societies have approached the process of election have been vague, to say the least.

Within the academy, the first step (in January) was a kind of popularity contest in which individual institutes put forward names for nomination. Sakharov and Sagdeev (in that order) came out on top, but then failed to win half the votes that might have been cast at the special conference a few weeks later. Now, 15 out of the 23 nominees still in the race have fallen for the same reason, no doubt victims of the advertised determination of those who wished to vote for Sakharov and Sagdeev to vote against all other candidates. Why, despite all the secret ballots, should candidates overwhelmingly popular at one stage of the election fail to be elected at the next? The immediate explanation is that the electorate changed (and narrowed) between the beginning of January and the end. And the explanation of that is that the academy, while seeking to give democratic processes an airing, did not dare go far down the road of one man, one vote.
Yet the Chamber of Deputies being elected is an important part of a new and more democratic system. Although it will meet only infrequently, it will have the crucial task of choosing the new Supreme Soviet, intended to become a full-time legislature under $\mathrm{Mr}$ Mikhail Gorbachev himself, who will be its president. It will have influence, even power. All the more reason why it should seem legitimate. Perhaps its first task should be to revise the law under which it is being elected, in the process abolishing the professional constituencies and the underlying principle of "most men, one vote: some men, two votes".

For the Soviet academy, the lessons to be drawn from this affair go even deeper. In the Soviet Union now, elections for institute directors, laboratory heads and others are all the rage. But on a matter such as the election of people to the Chamber of Deputies, which has nothing to do with the management of the academy's own over-complicated business, it is absurd that the academy should have canvassed the wishes of those working in its institutes and than have allowed them to be denied. If laboratory workers want Sakharov and Sagdeev to represent them, why should they not have their way?

\section{Cold (con)fusion}

Reports that an account of cold nuclear fusion is soon to appear in this journal are premature.

INCREASINGLY alert coverage of science by newspapers, taken as a sign of increasing public interest, is something that readers of this journal should applaud. But when scientists find themselves reading about their colleagues' discoveries in newspaper columns before anything has been submitted, let alone accepted or published, in a research journal, there is cause to be worried. No one was more surprised than the editors of Nature to learn, on reading last Friday's Wall Street Journal that two papers on room-temperature nuclear fusion (see page 364) would probably appear simultaneously in this journal, perhaps in May.

That editors of scientific journals are annoyed by this kind of event is due neither to sour grapes nor to a cabalistic devotion to secrecy. The procedure of peer- 